\title{
PROCESSO DE CAPACITAÇÃO DO OPERADOR DE SUPORTE MÉDICO (OSM) PARA PROCEDIMENTO DE SALVAMENTO EM ALTURA (SALT)
}

\author{
BENDER, Nádia ${ }^{1}$; SILVA, Rômulo do Nascimento ${ }^{2}$; ROSA, Alexsandro Marcos ${ }^{3}$; \\ SAFE, Jorge Costa ${ }^{4}$.
}

\section{RESUMO}

No universo atual das operações de resgate, os operadores de suporte médico (OSM) estão cada vez mais presentes nas equipes de salvamento em altura (SALT) com emprego de aeronaves. Este estudo teve como objetivo descrever o processo de capacitação dos operadores de suporte médico (OSM) de um serviço aeromédico do oeste catarinense em procedimentos de SALT. A metodologia utilizada foi um estudo de caso exploratório descritivo, com instrumento de coleta de dados a observação participante e análise documental do Manual de Operação Padrão (MOP) institucional. O processo de capacitação respeita o perfil técnico-operacional dos profissionais e é composto por etapas inter-relacionadas, iniciando pelo contexto teórico, perpassando pela parte técnico-prática até a simulação realística de resgates, objetivando tornar o OSM apto para a prática de SALT, sempre estimando pela segurança da operação. Constatou-se que a presença do OSM no contexto do SALT acarreta em inúmeros aspectos positivos para salvamento das vítimas, porém, como existem singularidade e especificidades dentro do procedimento em diferentes instituições, este deve ser devidamente capacitado e treinado para que se mantenha a segurança operacional dentro do aceitável.

Palavras-chave: Processo de capacitação, Resgate Aeromédico, Salvamento em Altura.

\section{INTRODUÇÃO}

O emprego de aeronaves em operações de resgate vem sendo implementado historicamente na prática de salvamento, a Guerra do Vietnã foi um marco importante no desenvolvimento dessa plataforma de resgate, na ocasião, eram utilizados helicópteros tripulados por dois pilotos, um médico e um tripulante (FRAME, 2017). Cardoso et al (2014), enfatizam que fatores como horário do dia, trânsito, distribuição das ambulâncias e local para onde o paciente será encaminhado, influenciam diretamente no tempo de atendimento pré-hospitalar, pois buscam estabelecer um tratamento eficaz no menor intervalo de tempo possível, aliando, possibilidade de acesso à vítima, tratamento inicial e transporte rápido, utilizando para isso o emprego de aeronaves.

1 Enfermeira do Serviço de Atendimento e Resgate Aeromédico - SARA.

2 Agente de Polícia Civil de Santa Catarina operador aerotático. (SAERFRON)

3 Médico Coordenador do Serviço de Atendimento e Resgate Aeromédico - SARA.

4 Agente de Polícia de Santa Catarina piloto do Serviço Aeropolicial de Fronteira (SAERFRON) 


\section{CON

No universo atual das operações de resgate, os operadores de suporte médico (OSM) estão cada vez mais presentes nas equipes. A operação aeromédica é permeada de inúmeras especificidades que exige um preparo diferenciado da equipe médica, principalmente no âmbito de salvamento em altura (SALT) que requer um processo de capacitação ainda mais específico. Gonzaga Jr. et al (2017), descreve que o resgate de Salvamento em Altura, consiste na remoção de pessoas, animais e/ou bens dos mais variados sinistros ou calamidades, com a finalidade de salvaguardar sua integridade física, psíquica tornando esse procedimento altamente especializado, exigindo dos socorristas um amplo conhecimento profissional.

Ainda que alguns procedimentos médicos estejam limitados devido à segurança operacional no SALT, a presença do OSM nessa modalidade de resgate pode contribuir positivamente no atendimento da vítima, através de cuidados prestados ainda no local da ocorrência e junto com o resgatista, avaliar e decidir a melhor forma de remoção da mesma. No entanto, a atuação do OSM somente será eficaz e positiva nessa modalidade de resgate, se esse operador passar por um processo de capacitação minucioso, regrado e constante para que este atue de forma segura, minimizando os riscos da operação. Freixo (2012) descreve que para a execução de Operações Aeromédicas, são necessárias inúmeras ações preparatórias, objetivando cumprir a missão dentro de um nível aceitável de segurança operacional, respeitando os procedimentos operacionais padrão, o regramento de treinamentos específicos e um constante gerenciamento de risco durante a execução dos voos.

Diante do exposto, o objetivo geral desse estudo é descrever o processo de capacitação dos operadores de suporte médico (OSM) de um serviço aeromédico do oeste catarinense com procedimentos de Salvamento em Altura (SALT), para alcance do objetivo supracitado foram delineados três objetivos específicos: identificar o perfil técnico-operacional da equipe médica; caracterizar as especificidades e particularidades da operação; e por fim discorrer sobre a atuação do OSM no cenário.

\section{METODOLOGIA}

Para a obtenção do objetivo proposto, foi realizado um estudo de caso do tipo exploratório descritivo, que conforme Yin (2015) é uma investigação empírica que 


\section{CON

investiga um fenômeno contemporâneo dentro de seu contexto de vida real. O instrumento de coleta de dados foi a observação participante e a análise documental do MOP institucional referente ao processo de capacitação de OSM de um serviço de atendimento e resgate aeromédico do oeste catarinense.

\section{RESULTADOS E DISCUSSÕES}

O perfil técnico - operacional dos OSMs do Serviço consiste em uma equipe de médicos e enfermeiros com ampla experiência em atendimento pré-hospitalar e suporte avançado de vida. A carga horária semanal dos profissionais não permite que o regime seja de dedicação exclusiva. Para compor a equipe, inicialmente foram submetidos a um Curso Prático de Adaptação em Aeronave e Resgate Aeromédico e mensalmente são submetidos a um cronograma de treinamento.

Em relação ao processo de capacitação, é muito importante considerar que o processo de formação do Operador Aerotático é distinto da formação do Operador de Suporte Médico e isso implica diretamente no processo de capacitação e treinamento da equipe médica.

Portanto, Nascimento (2017) descreve no Manual de Operação Padrão (MOP) Institucional do estudo, que dentre as peculiaridades que compõe a estrutura da técnica vertical, está a importância da padronização de procedimentos e a segurança na aplicação das técnicas repassadas. Ademais, o processo de Capacitação de SALT do OSM, respeita perfil técnico-operacional desse profissional, sistematizando o desenvolvimento da habilitação nesse tipo de resgate por meio de etapas inter-relacionadas que compreendem desde o contexto teórico, perpassando pela parte técnico - prática e só a partir de então a sequência prevê a simulação realística de situações de resgate. Paralelo a esse processo ocorrem cronograma de treinamentos periódicos para massificação dos processos. Conforme Nascimento (2017) existe diversos estilos e forma de aplicar a técnica vertical, na capacitação da unidade se atenta somente aos estilos negativos, guiado e de resgate, os quais acabarão se fundindo, pela singularidade de fazer parte das ações.

O processo de capacitação do OSM em salvamento em SALT, nunca se encerra, porém ao término da segunda etapa, a equipe de instrutores possuem elementos suficientes para tornar o operador apto ou não para prosseguir para a terceira etapa, ao final desta, a equipe de instrutores analisam se o profissional da 
equipe médica tem condições de atuar nesse tipo de operação sem oferecer riscos adicionais à atividade.

A presença do médico na cena pode ser um dos fatores que justifica a utilização do resgate aeromédico e os estudos evidenciaram um aumento na chance de sobrevida dos pacientes atendidos durante o resgate, quando comparado ao atendimento terrestre (ENCARNAÇÃO, ET AL 2014). Sendo assim, Nascimento (2017) ressalta que no procedimento sempre que necessário e possível o Médico(a) e Enfermeiro(a) devem realizar a descenção antes do Segundo Operador Resgatista, salvo por motivos que envolvem a segurança dos membros da equipe. $A$ ordem de descensão será proposta na ordem descrita: primeiramente o médico(a) e em sequência $a(0)$ enfermeira(o). Esta decisão só será subjugada, caso o Fiel decida pelo contrário; com fundamentação baseada na segurança de voo/operação, situação emocional e aptidão técnica dos integrantes da equipe médica.

Por fim, quanto a presença do OSM no cenário, o acesso acontecerá conforme as condições e necessidades avaliadas pelo Operador Aerotático/Resgatista. Com relação a qual OSM realizará a descenção, será considerado o critério de segurança técnica do operador, geralmente definido entre os membros da equipe médica. A respeito dos procedimentos médicos realizados na cena, serão implementadas as intervenções que possam contribuir para a melhor assistência possível, porém sem comprometer a segurança da operação.

\section{CONSIDERAÇÕES FINAIS}

Verificou-se que o OSM está cada vez mais presente nas esquipes de resgate, este evento tem inúmeros aspectos positivos, desde que esse profissional esteja muito bem treinado e seguro para atuar nesse tipo de atendimento visando sempre a segurança operacional. O processo de capacitação deve respeitar o perfil técnico - operacional da equipe médica e seguir um roteiro organizado pautado no Manual de Operações (MOP) institucional. A presença OSM no cenário será apropriada quando o Operador Aerotático/Resgatista entender que a vítima se beneficiará de intervenções médicas in loco, prestando a melhor assistência possível dentro do que a segurança operacional permite. Por fim, as referências bibliográficas com experiências das equipes médicas em salvamento em altura (SALT) ainda é escassa, sugere-se mais estudos e registros dessa prática no contexto aeromédico. 


\section{REFERÊNCIAS}

CARDOSO, Ricardo Galesso; FRANCISCHINI, Carina Fontana; RIBERA, Jorge Michel; VANZETTO, Ricardo ; FRAGA, Gustavo Pereira. Resgate aeromédico a traumatizados: experiência na região metropolitana de Campinas, Brasil. Revista do Colégio Brasileiro de Cirurgiões. Jul 2014; Vol. 41(4): pp. 236-244 .

ENCARNAÇÃO, Paula Soares; MELO, Maria Manuela; LAGE, Maria Isabel. A Pessoa em Situação Crítica Helitransportada: história do passado recente e panorama atual. Revista de Enfermagem Referência. Coimbra, v. IV, n. 2, p. 171-183, jun. 2014 .Disponível em <http://scielo.pt/scielo.php?script=sci_arttext\&pid=S087402832014000200018\&lng=p t\&nrm=iso>. Acesso em: 22 jul. 2021.

FRAME Carson. Modernas práticas de resgate aeromédico tiveram suas origens na Guerra do Vietnã. Disponível em: $<$ https://www.resgateaeromedico.com.br/modernas-praticas-de-resgate-aeromedico-

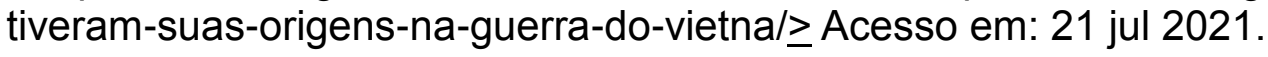

FREIXO José Alexander de Albuquerque. Segurança de voo em Operações de Resgate Aeromédico do GRPAe/SP. Disponível em: $<$ https://www.pilotopolicial.com.br/seguranca-de-voo-em-operacoes-de-resgateaeromedico-do-grpaesp/> Acesso em: 21 jul 2021.

GONZAGA Jr. Hélio Loyola; CARDOSO Eduardo Campos; REIS Sayro Geane Oliveira dos. Manual Operacional de Bombeiros Salvamento em Altura. Goiânia: Secretaria Geral do CBMGO, 2017, 334 p.

NASCIMENTO, Rômulo. Manual Operacional Padrão - MOP. Resgate em Altura - Aeronave Policial. Chapecó, Serviço Aeropolicial de Fronteira - SAERFRON 2021. 52 p.

YIN, Robert K. Estudo de Caso: planejamento e métodos. 5 Edição. Porto Alegre, Bookman, 2014. 320p. 